\title{
ArcheoSciences
}

Revue d'archéométrie

\section{Preliminary Experiments on Model Artificially Altered Samples to Consolidate Degraded and Wet Archaeological Bone with Azelaic Acid}

Expériences préliminaires réalisées sur des échantillons modèles altérés artificiellement pour consolider l'os archéologique humide et dégradé par l'acide azélaïque

Gilles Chaumat, Katharina Müller and Ina Reiche

\section{(2) OpenEdition}

\section{Journals}

Electronic version

URL: https://journals.openedition.org/archeosciences/3219

DOI: 10.4000/archeosciences.3219

ISBN: 978-2-7535-1849-0

ISSN: $2104-3728$

Publisher

Presses universitaires de Rennes

\section{Printed version}

Date of publication: 30 April 2011

Number of pages: $213-222$

ISBN: 978-2-7535-1847-6

ISSN: $1960-1360$

\section{Electronic reference}

Gilles Chaumat, Katharina Müller and Ina Reiche, "Preliminary Experiments on Model Artificially Altered Samples to Consolidate Degraded and Wet Archaeological Bone with Azelaic Acid", ArcheoSciences [Online], 35 | 2011, Online since 30 April 2013, connection on 02 March 2022. URL: http://journals.openedition.org/archeosciences/3219; DOI: https://doi.org/10.4000/archeosciences. 3219 


\title{
Preliminary Experiments on Model Artificially Altered Samples to Consolidate Degraded and Wet Archaeological Bone with Azelaic Acid
}

\author{
Expériences préliminaires réalisées sur des échantillons modèles altérés artificiellement \\ pour consolider l'os archéologique humide et dégradé par l'acide azélaïque
}

\author{
Gilles Chaumat*, Katharina MüLler ${ }^{* *}$, Ina Reiche ${ }^{* *}$
}

\begin{abstract}
As treatments of degraded and wet archaeological bone material is a delicate challenge, no dedicated conservation protocol for this rare material is available today for restorers or museum curators. The current bulking agents have difficulties to diffuse into the close and dense osseous structure. This work aimed at testing the efficiency of an original resin formulation to consolidate in the volume, wet archaeological materials. The tested resin was azelaic acid, a carboxylic diacid comprising nine carbon atoms in its aliphatic chain. Azelaic acid possesses a melting point over more than $100^{\circ} \mathrm{C}$ and an amazing amphiphile property: azelaic acid is hydrophilic and water soluble at high temperature $\left(70^{\circ} \mathrm{C}\right)$ and hydrophobic at room temperature. Consequently, it was proposed to carry out the treatment at $90^{\circ} \mathrm{C}$ for permitting a good diffusion of acid in the bone porosity, followed by a simple cooling to solidify the resin.

The first preliminary characterization results of modern compact bone samples that are artificially degraded, showed the effective permeation of all the volume of the altered osseous material by azelaic acid. The rigidity of the bone seemed to be increased by the consolidation treatment, but could not be quantified so far.
\end{abstract}

\begin{abstract}
Résumé : Les matériaux osseux archéologiques humides font parties des matériaux fragiles difficiles à traiter pour leur conservation. Ainsi, il n'existe à l'heure actuelle pas de protocole de conservation disponible aux restaurateurs et conservateurs de musée. Les résines de consolidation utilisées en restauration sont en général incapables de diffuser au sein de la structure dense et fermée de l'os. Pour répondre à ce problème, nous avons testé l'efficacité d'une nouvelle formulation de produit pour consolider les matériaux osseux archéologiques humides dans tout leur volume.

L'acide azélaïque (diacide aliphatique carboxylique à neuf carbones) a été sélectionné car il présente une propriété atypique : il est hydrophile et soluble dans l'eau à des températures supérieures à $70^{\circ} \mathrm{C}$ et redevient lipophile et hydrophobe à température ambiante en se solidifiant. Des essais d'imprégnation à $90^{\circ} \mathrm{C}$ ont été réalisés pour permettre une bonne diffusion de la résine dans la porosité de l'os, suivis par un simple refroidissement à l'air libre.

La campagne de caractérisation préliminaire, réalisée à partir d'échantillons d'os compact vieilli artificiellement, a montré que ce produit a pu diffuser dans tout le volume du tissu osseux et qu'apparemment une consolidation a été obtenue, même si celle-ci n'a pas encore été quantifiée, car l'échantillon consolidé est moins friable.
\end{abstract}

Keywords: consolidation, artificially altered bone, azelaic acid, SEM, FTIR, $\mu$ PIXE.

Mots clés : consolidation, os vieilli artificiellement, acide azélaïque, MEB, IRTF, $\mu P I X E$.

* ARC-Nucléart, CEA-Grenoble, 17 rue des Martyrs, 38054 Grenoble. (gilles.chaumat@cea.fr)

** UMR - 171 CNRS Laboratoire du Centre de Recherche et de Restauration des Musées de France, Palais du Louvre, 14 Quai François-Mitterrand, 75001 Paris. (katharina.mueller@culture.gouv.fr) (ina.reiche@culture.gouv.fr) 


\section{INTRODUCTION}

Archaeological bones or artefacts made of bone are sensitive to collagen degradation [1-3]. For instance the "crosier of the tomb of Hardouin de Bueil" kept in the cathedral St. Maurice of Angers dating from $14^{\text {th }} \mathrm{c}$. is in an alarming state of conservation (fig. 1). Generally, osseous materials need to be impregnated with resins to be kept or exhibited over long times in museums. Resins usually used to consolidate dry bone are Paraloid B72, Rhodopas [4]; whereas the main resin to treat archaeological wet bone is polyethylene glycol (PEG) [5-6]. For the last case, the Polyethylene Glycol (PEG) resin is useful to consolidate the degraded osseous structure and to limit the stress of material during its drying.

Bone materials are among the archaeological organic materials the most delicate to preserve and treat. Indeed, osseous objects are complex biominerals made of a strong combination between mineral (carbonated hydroxyl-apatite) and organic phases (mainly collagen) with a very low open porosity available (even for degraded material). Moreover, unlikely flexible wood or leather, the degraded osseous materials combine several inconveniences: a high sensitiveness to the air moisture content, a strong stiffness associated with an important brittleness of the structure, a low open porosity unsuitable for bulking resin impregnation favouring osmotic phenomena and above all, a double extreme heterogeneity: a chemical heterogeneity with an association of mineral components with organic material and a morphologic heterogeneity coming from the high structural hierarchy with a very dense external ring of bony structure around a very porous core. Furthermore, there is no characterisation protocol well suited to establish diagnostic preservation states of the bone material, which can vary considerably as a function of the storage or the burial conditions of the artefact.

ARC-Nucléart gained several tens of years experience in the field of archaeological bone material treatment. Important collections of wet antlers from Jura lakes as Chalain (Neolithic period) were yet treated (fig. 2). The chosen protocols are based on PEG impregnation followed by a controlled air-drying phase. A treatment has been defined from important work done by Hug and Hiron [5]. Nevertheless, some breaks or cracks are still observed on 8 to $10 \%$ of the treated material, especially during the last steps of the drying process.

Among, the considerations, it appears that impregnation resins as PEG seem not to be appropriate for bone consolidation as they cannot diffuse easily inside the dense part of the bone [6]. Therefore, a solution using PEG may be dangerous due to the risk of osmotic drying of bone during its impregnation treatment. Moreover, even if the use of

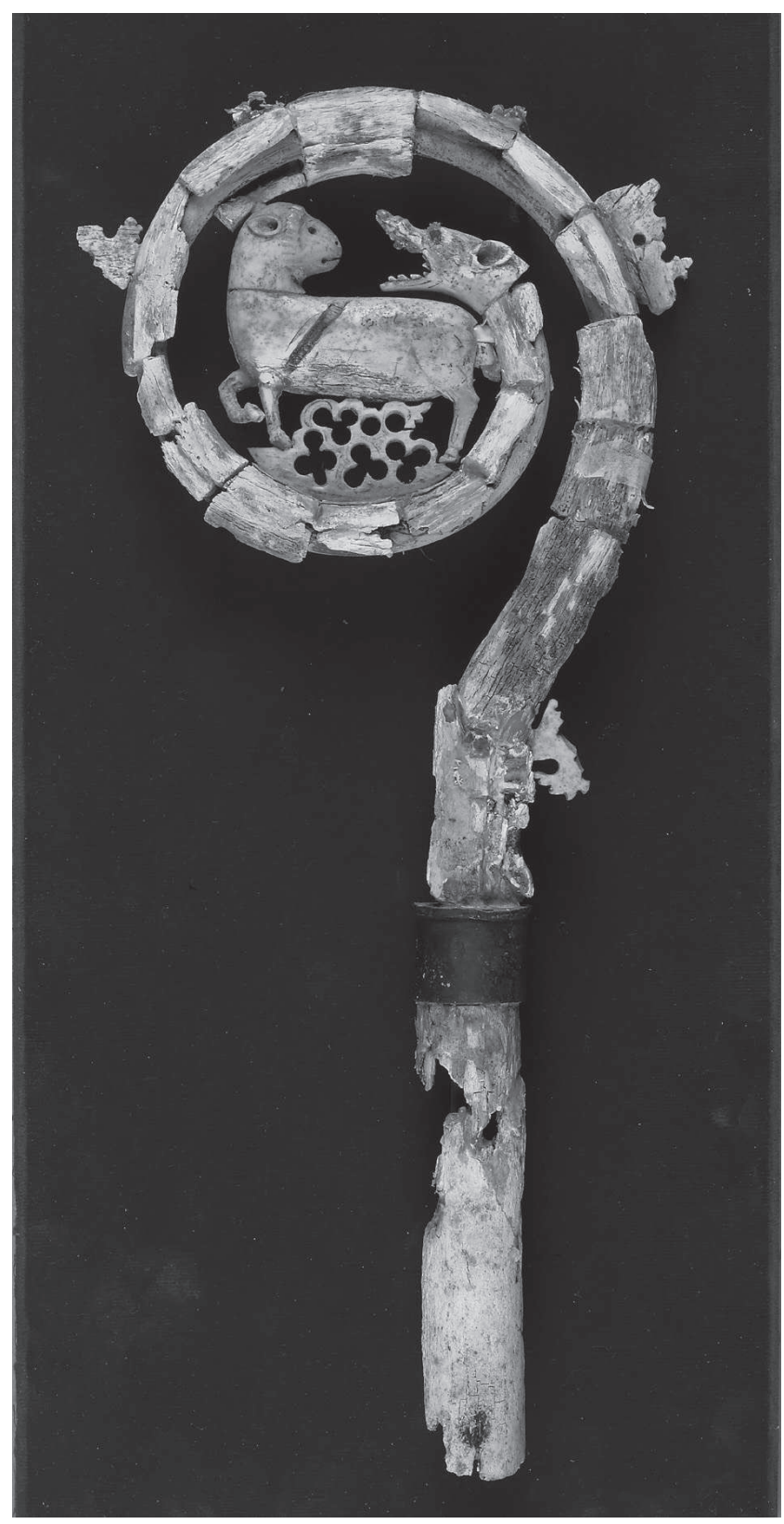

Figure 1: (See colour plate) "Crosier of the tomb of Hardouin de Bueil" kept in the St. Anne's chapel of the St. Maurice cathedral of Angers dating from the 14th c. (inv. no. 58, 36.5x15.7x3 cm3). (C) C2RMF, D. Bagault.

Figure 1: (Voir planche couleur) "Crosse du tombeau de Hardouin de Bueil " conservée dans la Chapelle Saint Anne de la cathédrale St

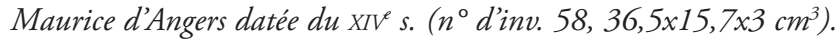
(C) C2RMF, D. Bagault.

PEG 400 limits the material stress against shrinkage, it does not provide a sufficient consolidation of a crunchy material. Consequently, it is very difficult to identify specific resins able to diffuse into this dense composite material and able 


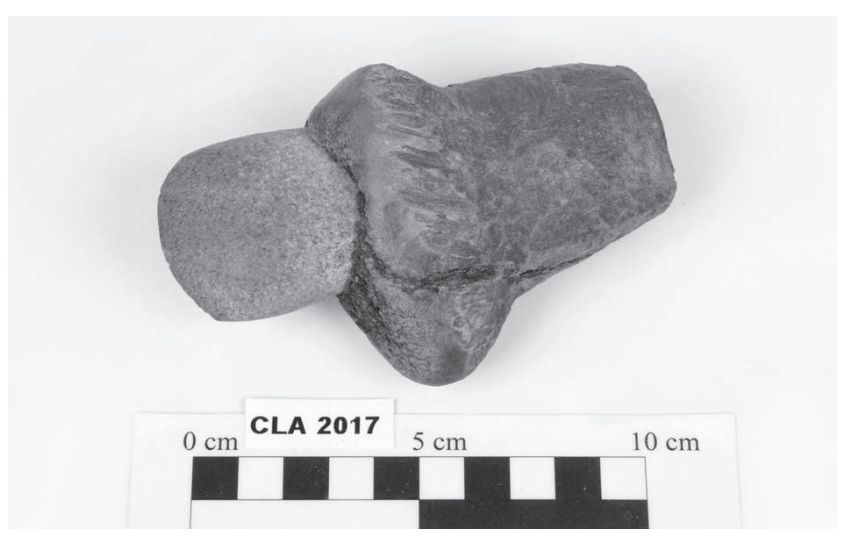

Figure 2: (See colour plate) Archaeological antler from Neolithic Clairvaux site. CARC-Nucléart C. Terpent.

Figure 2 : (Voir planche couleur) Andouiller archéologique provenant du site néolithique de Clairvaux. (C) ARC-Nucléart C. Terpent.

to replace bound water. The purpose of this study is focused on the establishment of new consolidant resins appropriate for the treatment of archaeological wet bone. According to general conservation rules, the "ideal" bulking resin should meet the following criteria:

- melting point higher than $60^{\circ} \mathrm{C}$,

- hydrophobic at room temperature,

- a simple and non toxic molecule,

- commercially available and inexpensive formulation,

- a system that is non-reactive with bone (only "hydrogen bonding" is considered).

Here it was proposed to test azelaic acid (a diacid carboxylic involving nine carbons and in solid state at room temperature) as alternative of PEG to treat bone material. It has been chosen for its peculiar and original properties as described below.

\section{Azelaic acid and its properties}

\section{Structure of azelaic acid}

Azelaic is an aliphatic saturated molecule with two carboxylic functions at the end of a nine-carbon central chain. The chemical formula of azelaic acid is $\mathrm{HOOC}-\left(\mathrm{CH}_{2}\right)_{7}-$ $\mathrm{COOH}$ and melting point is at $110^{\circ} \mathrm{C}$.

There are two advantages in selecting a fatty acid system. First, the molecule's structure is very simple and aliphatic without any "sensitive" function in the central straight chain, and consequently good resistance to heat and light is expected, even in atmospheric oxygen.

Additionally, it is amphiphile. The central part of the molecule, which has a - $\left(\mathrm{CH}_{2}\right)$ - pattern, may be considered to be hydrophobic, unlike the end carboxylic acid function, which is very polar, very hydrophilic, able to form a strong "hydrogen bond". The choice of molecule must be based on the balance between these two opposite behaviour patterns in the same molecule. The chain length and number of carboxylic functions enable the relative contributions to be adjusted. The molecules selected must guarantee a generally hydrophobic behaviour at room temperature in order to ensure little interaction between the treated artefact and the relative humidity of the air. Nevertheless, the polarity of the resin molecule must be sufficient to ensure good affinity and linkage between the bulking agent and hydrophilic collagen in bone. It is expected that the fatty acid may enter the open porosity to replace bound water and then avoid excessive shrinkage as the archaeological artefacts drying.

The choice to use dicarboxylic acid with a shorter chain (as adipic acid with six carbons) is not consistent because the product is more hydrophilic and more acid, i.e. more unstable and sensitive to climatic conditions.

\section{The water solubility of fatty acids}

Azelaic acid formulation was chosen because it is almost insoluble in water at room temperature. This property is interesting because, unlike PEG resin, fatty acids are usually hydrophobic. However, this feature leads to a major difficulty: how a wet bone based artefact can be treated with a resin that is insoluble in water?

To solve this problem, a specific property of azelaic acid was used. At $70^{\circ} \mathrm{C}$, azelaic acid is water-soluble. Figure 3 shows the phase diagram of azelaic acid with water. This property is very interesting, because it means in theory that it is possible to dissolve azelaic acid in water for bone impregnation at high temperature and during cooling, the resin becomes insoluble, and consequently azelaic acid expels its water and becomes a solid hydrophobic consolidant.

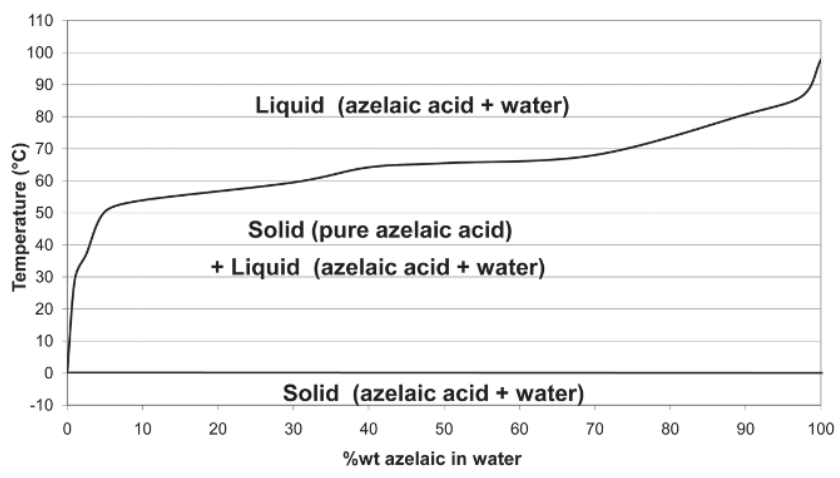

Figure 3: Behaviour of azelaic diacid with water: the phase diagram water/ azelaic diacid versus temperature.

Figure 3 : Comportement de l'acide azélaïque avec l'eau: diagramme de phases eaulacide azélä̈que en fonction de la température. 
The second interesting and potential property of azelaic acid is the molecular size (molar weight $=188$ ), about two times lower than that of PEG 400. The hydroxide functions of PEG are replaced by two carboxylic functions in the azelaic formulation; it is expected that this function, with a better polarity, allows a better diffusion of this resin into the bone matrix compared to that of PEG in bone.

\section{Materials and Methods}

\section{Representative bone samples}

One of the main difficulties for launching an effective research programme on bone consolidation is to provide relevant degraded humid archaeological samples. Basically, two difficulties were encountered when chosen bone materials for the experiments:

- archaeologists can offer only a limited quantity of bone material for research works;

- archaeological bone can display a great variety of alteration states caused by diagenetic processes and a chosen degraded bone is therefore not always appropriate to serve as a model for systematic preservation treatments. Indeed, it is not possible to forecast if a wet archaeological bone material can sustain or not to its drying.

Consequently, for implementing this study, it was decided to manufacture artificially degraded modern bones, where the alteration processes can be controlled by the aging conditions. We chose aging conditions sufficiently hard to be sure that bone materials cannot hold their drying. Obviously, we cannot guarantee that the chosen aging conditions are fully representative of the natural degradation of archaeological bone. Nevertheless, the main purpose of this preliminary work is to demonstrate that an active diffusion of a bulking agent in the intimate structure of a bony dense material is possible.

\section{Aging and consolidation procedure}

Aging modern bone samples came from beef origin (tibia) taken in the compact osseous structure (without periosterum layer). The sample's sizes are of $20 \times 8 \times 4 \mathrm{~mm}^{3}$. Three bone samples were used as follows:

- The sample (CEA ref) is the reference sample without any aging treatment.

- According to an important preliminary work carried out, not disclosed in this publication, it was decided to treat the bone with a moderated potash solution $(6 \mathrm{~g} \mathrm{KOH} / \mathrm{l}$ $\left.\mathrm{d}^{\prime} \mathrm{H}_{2} \mathrm{O}\right)$ during $48 \mathrm{~h}$ at $90^{\circ} \mathrm{C}(\mathrm{CEA} 1)$. By this treatment the bone samples (CEA1) lost about $30 \%$ of their weight and swelled slightly. The mechanical properties of the material changed drastically: it can be crushed easily by finger pressure. The degradation seems homogeneous in all the sample volume.

- After aging, the bones were consolidated using a solution of azelaic acic (90 wt.\%) involving water (10 wt.\%). The $\mathrm{pH}$ is close to 2 . The samples were kept at $90^{\circ} \mathrm{C}$ in a drying oven for $24 \mathrm{~h}$ (CEA2). After cooling, samples were weighted and the weight increase due to the consolidant uptake was close to $50 \%$.

\section{Analytical methods}

One artificially altered (CEA1) and one consolidated bone (CEA2) as well as an untreated reference (CEA_ref) were analyzed by means of scanning electron microscopy (SEM), infrared spectroscopy (FTIR) and microbeam Particle induced X-ray emission analysis ( $\mu$ PIXE).

The morphological observations have been carried out by means of the scanning electron microscope XL $30 \mathrm{CP}$ (Philips) equipped with the energy-dispersive X-ray detection system Link Isis 300 (SEM/EDX). The applied acceleration tension was $20 \mathrm{kV}$ leading to a current of about $100 \mu \mathrm{A}$. For the SEM analyses transversal cross-sections of the bones were cut with a diamond saw, polished and afterwards coated with carbon. No sample cleaning in an ultrasonic bath was carried out to avoid partial dissolution of the mineral fraction of the degraded bone sample. An alteration of the samples during SEM observations could not be observed.

The Fourier transform infrared spectroscopy (FTIR) analyses were conducted with the spectrometer Spectrum 2000 (Perkin Elmer) in transmission mode using a diamond cell. Very small quantities (less than one milligramm) of material are needed for these analyses. Therefore, it was possible to take small samples at the borders and in the center of the cross sections and to perform structural investigations at three points of the sample. The IR spectra were collected in the range between 4000 and $400 \mathrm{~cm}^{-1}$ with a resolution of $4 \mathrm{~cm}^{-1}$. Twenty scans were accumulated per spectrum. Data evaluation was performed with GRAMS software. After baseline correction distinctive absorbance intensities were determined to calculate specific parameters characterizing the preservation state of bone mineral and organic phases. The preservation of the organic phase can be characterized by the collagen content expressed as amide I $\left(1660 \mathrm{~cm}^{-1}\right)$ to phosphate $\left(1035 \mathrm{~cm}^{-1}\right)$ band ratio. The mineral phase can be described by the IR splitting factor (IRSF) based on the phosphate vibration bands at $565 \mathrm{~cm}^{-1}$ and $605 \mathrm{~cm}^{-1}$ and the carbonate content 
represented by the intensity ratio of the main carbonate band at $1415 \mathrm{~cm}^{-1}$ and the phosphate band at $1035 \mathrm{~cm}^{-1}[7-8]$.

Element concentration profiles were obtained by several analyses along a profile between the borders on the different bone sections using micro-Proton induced $\mathrm{X}$-ray emission spectroscopy ( $\mu$ PIXE). The analyses were conducted at the external micro-beam line at the $2 \mathrm{MV}$ tandem particle accelerator AGLAE at the LC2RMF, Paris [9]. Measurements were taken in steps of $300 \mu \mathrm{m}$ for CEA1 and $500 \mu \mathrm{m}$ for the reference and CEA2. For each measuring point an area of $300 \times 300 \mu \mathrm{m}^{2}$ or $500 \times 500 \mu^{2}$ was scanned as a function of the step size to obtain continuous profiles. The PIXE data were evaluated with the software GUPIX based on fundamental parameter method [10].

\section{Characterization}

The altered bone sample (CEA1) appeared very brittle and not easy to cut or polish, whereas the consolidated bone sample (CEA2) was less fragile and more easily to handle. White crystals were deposited in more or less thick layers on the bone surface.

Figure 4 displays back scattered electron (BSE) micrographs of the analyzed bone samples. For all samples the histological units of secondary bone structure, called osteons (consisting of lamellae concentric arranged around the Haversian channels), could be observed. No specific differences in the morphological appearances between the unaltered bone reference (CEA_ref, fig. 4a), the altered sample (CEA1, fig. 4b) and consolidated sample (CEA2, fig. 4c) were detected. The sample preparation for the SEM analysis had to be done without cleaning in an ultrasonic bath - although it is common praxis - because the ultrasonic treatment may cause partial dissolution of the material particularly along the polishing traces and around the osteons (fig. 4d). This indicates a high degree of degradation of the artificially altered bone.

No extensive accumulation of crystallized consolidation material was observed for the consolidated sample CEA2. Energy dispersive X-ray analytical measurements in the inner region of the osteon close to the Haversian channel revealed enhanced carbon and oxygen concentrations corresponding to an enrichment of organic material. This observation indicates that the consolidation products were deposited in a thin layer at the wall of the Haversian channels (fig. 5b). However, the cavities of the bone (Haversian channels and cavities of the osteocytes) are kept predominantly unfilled. In general, the consolidation material seemed to be homogeneously distributed.
In order to get an insight into the preservation state of the organic (collagen) and the mineral part (carbonated hydroxyapatite, carb-HAP) the bones have been analyzed by FTIR-spectroscopy. Figure 6 shows the IR spectra of the bone reference and the artificially altered bone CEA1 within the region of interest between 400 and $2000 \mathrm{~cm}^{-1}$. All typical vibration bands of bone are indicated in this figure: the amide I, II and III bands originating from collagen, the different phosphate as well as carbonate bands correlated with carb-HAP. All bands referring to the presence of collagen are absent in the spectrum of CEA1. Obviously, the collagen has been completely destroyed due to the aging treatment. The IRSF of CEA1 is slightly elevated (3.1) in comparison with the reference sample (2.8) that corresponds to some increase of apatite crystallinity meaning an alteration of the mineral bone phase. By contrast, the carbonate content obtained for CEA1 $(\sim 0.35)$ is decreased compared to the one of the reference sample $(-0.55)$ meaning that carbonate got lost during the aging procedure.

The FTIR spectra measured at different points of sample CEA2 (external as well as central regions) were all characterized by the presence of characteristic vibration bands of carboxylic acids: $\mathrm{C}-\mathrm{O}$ vibration band between 1000 and $1300 \mathrm{~cm}^{-1}$ (overlapping with $v_{1} v_{3} \mathrm{PO}_{4}^{3-}$ ), $\mathrm{C}=\mathrm{O}$ vibration band at $1680-1730 \mathrm{~cm}^{-1}$, C-H vibration band at 2800 $3000 \mathrm{~cm}^{-1}$ and the very broad $\mathrm{C}-\mathrm{H}$ vibration band between 2500 and $3300 \mathrm{~cm}^{-1}$ (overlapping with the $\mathrm{C}-\mathrm{H}$ vibration band) (fig. 7). Therefore, it can be assumed that the consolidation material was distributed all over the sample.

The measured FTIR spectra also allowed evaluating the effect of the consolidation procedure on the crystallinity of the bone apatite phase and the carbonate content. The IRSF of CEA2 is 3.3 indicating a slight enhancement in comparison to the aged CEA1 sample in contrast to the carbonate content of CEA2, which stays sensitively the same $(\sim 0.38)$ in comparison to that of the CEA1 sample.

The element concentration distribution of the bone sections of CEA1 and CEA2 could be recorded by elemental profiling using $\mu \mathrm{PIXE}$ analyses, repeated twice as shown in fig. 8, of the following elements: sodium, magnesium, aluminum, silicon, phosphorous, potassium, calcium, zinc and strontium. The PIXE measurements leave slight visible traces on the samples indicating a small beam-induced damage of the samples that has to our knowledge no significant impact on the quantitative results. The concentration profiles of these elements are displayed in fig. 9. No specific variation in the element concentration between the inner and the outer region of the artificially altered sample (CEA1) was observed. The chemical composition of this sample (CEA1) varied only in the potassium, sodium and silicon contents from that one 

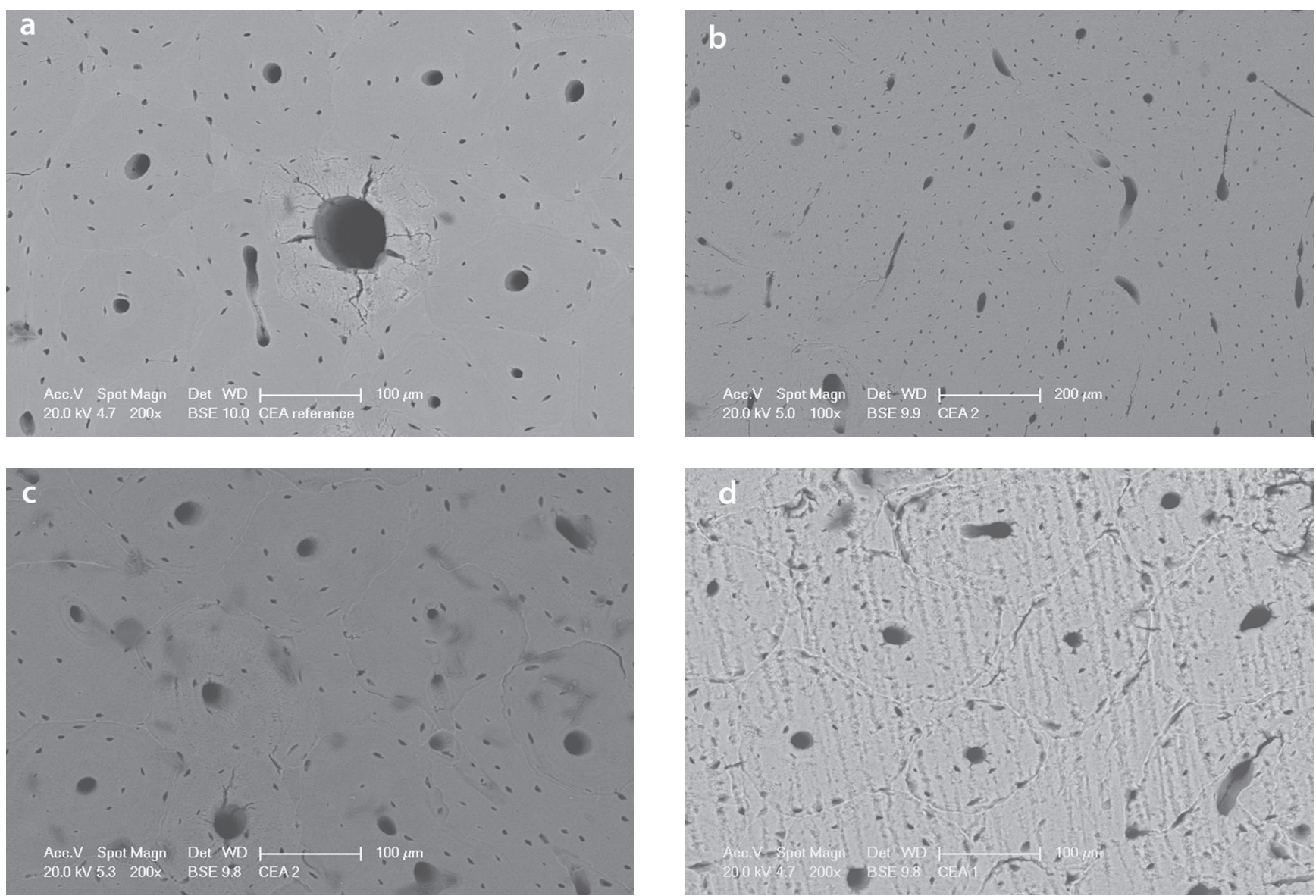

Figure 4: Backscattered electron micrographs of the modern bone reference (CEA_ref) (a), the artificially altered sample (CEA1) (b), the consolidated sample (CEA2) (c) and the sample (CEA1) after cleaning in an ultrasonic bath for several minutes (d). Figure 4: Micrographie en électrons rétrodiffusés d'un os moderne référence (CEA_ref) (a), d'un échantillon vieilli artificiellement (CEA1) (b), d'un échantillon consolidé (CEA2) (c) et de l'échantillon (CEA1) après nettoyage dans un bain par ultra-sons pendant quelques minutes (d).
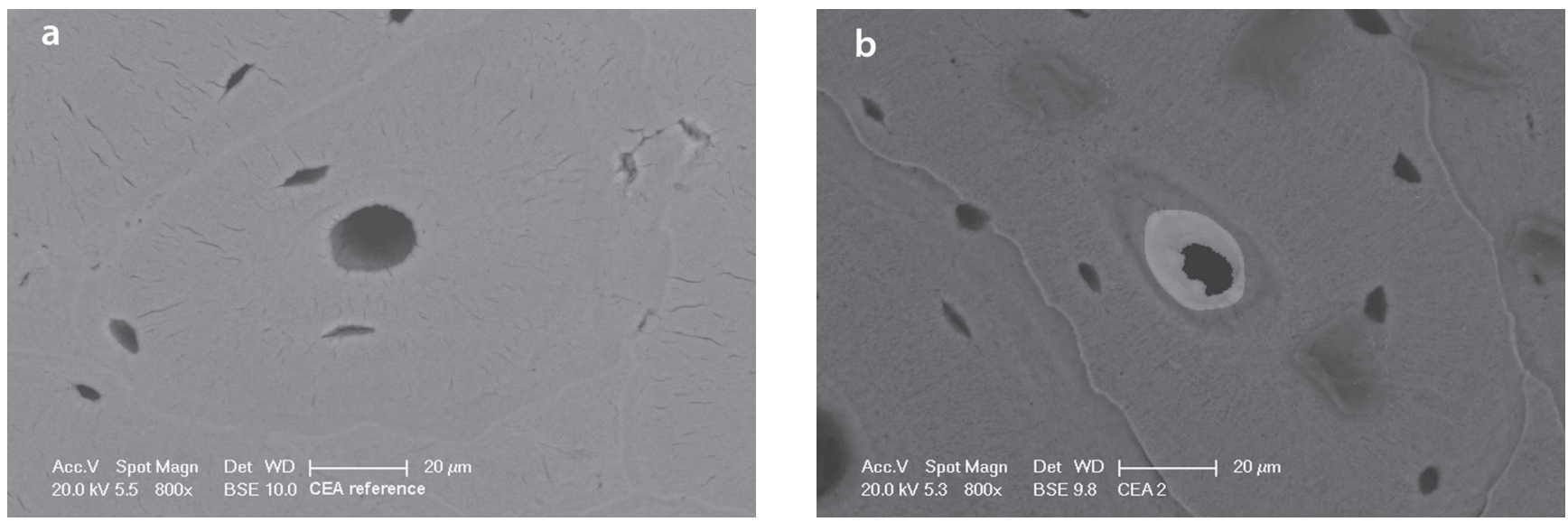

Figure 5: High magnification backscattered electron micrographs of the modern bone reference (CEA_ref) (a) and the consolidated bone sample (CEA2) (b). The area marked in light grey corresponds to the consolidation product.

Figure 5: Micrographies haute résolution en électrons rétrodiffusés d'un échantillon référence (CEA_ref) (a) et de l'échantillon consolidé (CEA2) (b). La zone marquée en gris clair correspond au produit de consolidation. 
Figure 6: IR spectra of the bone reference (center of CEA_ref) and the artificially altered bone (border of CEA1). The characteristic vibration bands for bone are indicated.

Figure 6 : Spectre infrarouge de l'échantillon référence (centre de CEA_ref) et de l'échantillon vieilli artificiellement (bord de CEA1). Les caractéristiques des bandes de vibration pour l'os sont indiquées.
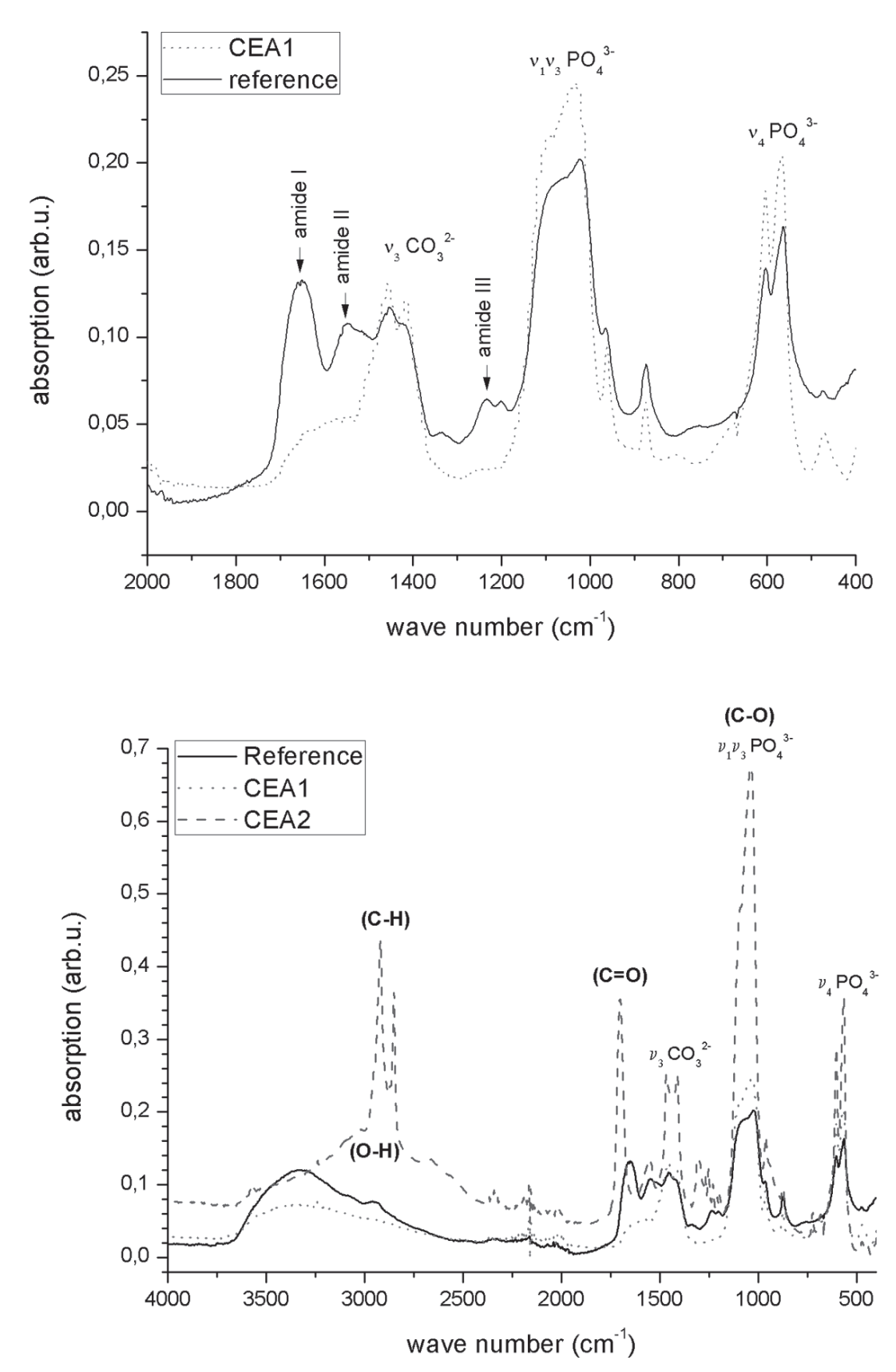

Figure 7: IR spectra of the modern bone reference (center of CEA_ref), the artificially altered (border of CEA1) as well as the subsequently consolidated bone sample (center of CEA2).

Figure 7 : Spectre infrarouge de l'échantillon d'os moderne référence (centre de CEA_ref), de l'échantillon vieilli artificiellement (bord de CEA1) et de l'échantillon d'os consolidé (centre de CEA2). of the reference. The most pronounced change was found for the potassium content, which is significant increased in CEA1 (up to four times higher than in the reference sample, CEA_ref). Apparently, potassium originating from the aging solution $(\mathrm{KOH})$ has been enriched in the bones. The sodium content has been decreased and the silicon content has been increased, by about 30\% respectively, during the aging procedure. It is conceivable that sodium was replaced by potassium. The origin of silicon could eventually be explained by the use of Pyrex glass vessels as a recipient for the attack in the alkaline solution. Silicon could be leached out of the glass by the alkaline solution and therefore be available in solution for uptake in bone.

By comparing the elemental distribution profiles of the aged sample (CEA1) and the consolidated sample (CEA2), as shown in fig. 10, several chemical changes could be found. For the potassium content of sample (CEA2), a concentration profile with clearly decreased concentrations in the external region was observed. The other elements were more or less homogeneously distributed all over the sample. The contents of potassium, sodium and magnesium have been decreased caused by the consolidation procedure, in particular that 


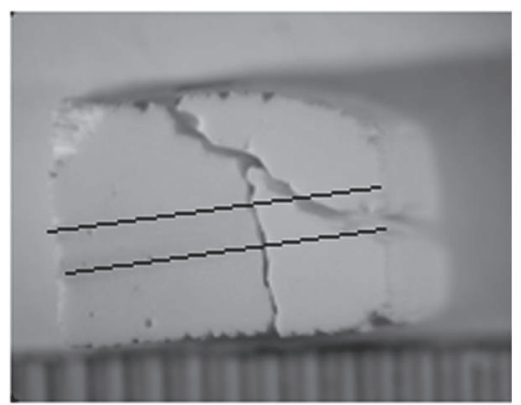

CEA 1
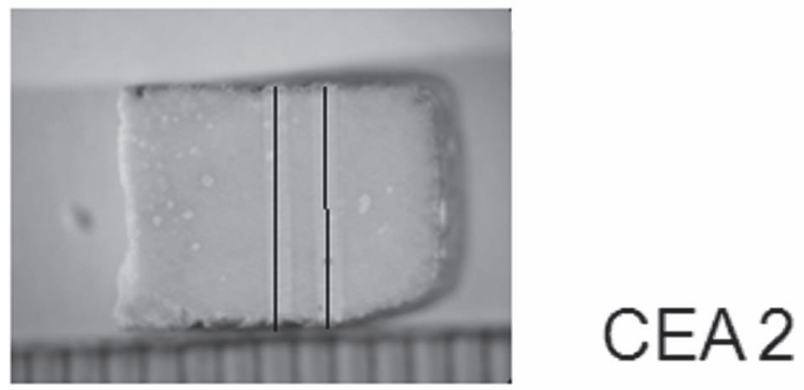

Figure 8: (See colour plate) Image of the artificially altered model sample (CEA1) with measured PIXE concentration profiles indicated as well as that of the altered and subsequently consolidated model sample CEA2 with the indicated PIXE concentration profiles.

Figure 8: (Voir planche couleur) Image de l'échantillon altéré artificiellement (CEA1) avec l'indication des profils de concentration PIXE mesurés ainsi que celle de l'échantillon altéré et puis consolidé (CEA2) avec profils de concentration PIXE mesurés indiqués. of potassium (down to half of the concentration in CEA1). Evidently, the potassium first introduced by the aging solution was then at least partly washed out by the consolidation process. Additionally, a slight decrease of the magnesium content and a very slight decrease of the sodium content could be established. Apparently, these elements were partly dissolved by the acidity of the consolidation solution. The dissolution effect is stronger in the external region of the sample that is more exposed during the treatment than the internal parts.

\section{DisCussion}

\section{Artificial aging}

In this work, one aging method was used for providing artificially altered bone samples (treatment with basic solution of moderate concentration in heat). Though there are no specific differences observed in micro-morphological observations before and after aging, changes in macroscopic features are spectacular:

- Strong mechanical alteration (after aging, sample appeared macroscopically very fragile and crusty).

- According to the FTIR analyses, the bone collagen was obviously destroyed due to the aging procedure.

- A 30\% weight loss is measured after aging treatment.

In parallel, the aging process modified the chemistry of the materials as follows:

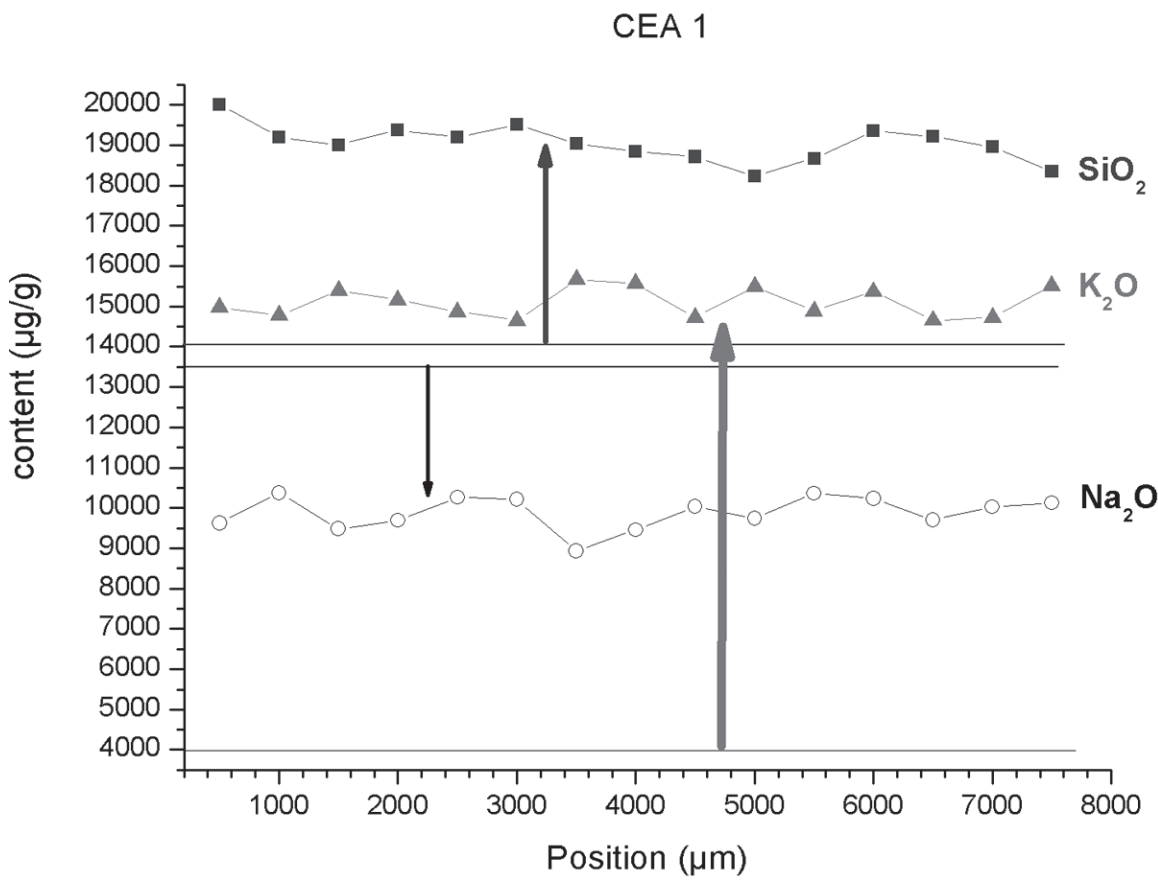

Figure 9: Concentration profiles for the artificially altered sample (CEA1) in comparison to the contents of the respective elements in the reference bone sample (CEA_ref) (marked as horizontal lines)

Figure 9: Profils de concentration des éléments constitutifs de l'échantillon artificiellement vieilli (CEA1) comparés avec les concentrations de l'échantillon de référence (CEA_ref) (représentées par les lignes horizontales). 


\section{CEA 2}

Figure 10: Concentration profiles for the consolidated sample (CEA2) in comparison to the contents of the respective elements in the altered sample (CEA1) (marked as horizontal lines) Figure 10 : Profils de concentrations des éléments constitutifs de l'échantillon consolidé (CEA2) comparés à celles de l'échantillon vieilli artificiellement (CEA1) (représentées par les lignes horizontales).

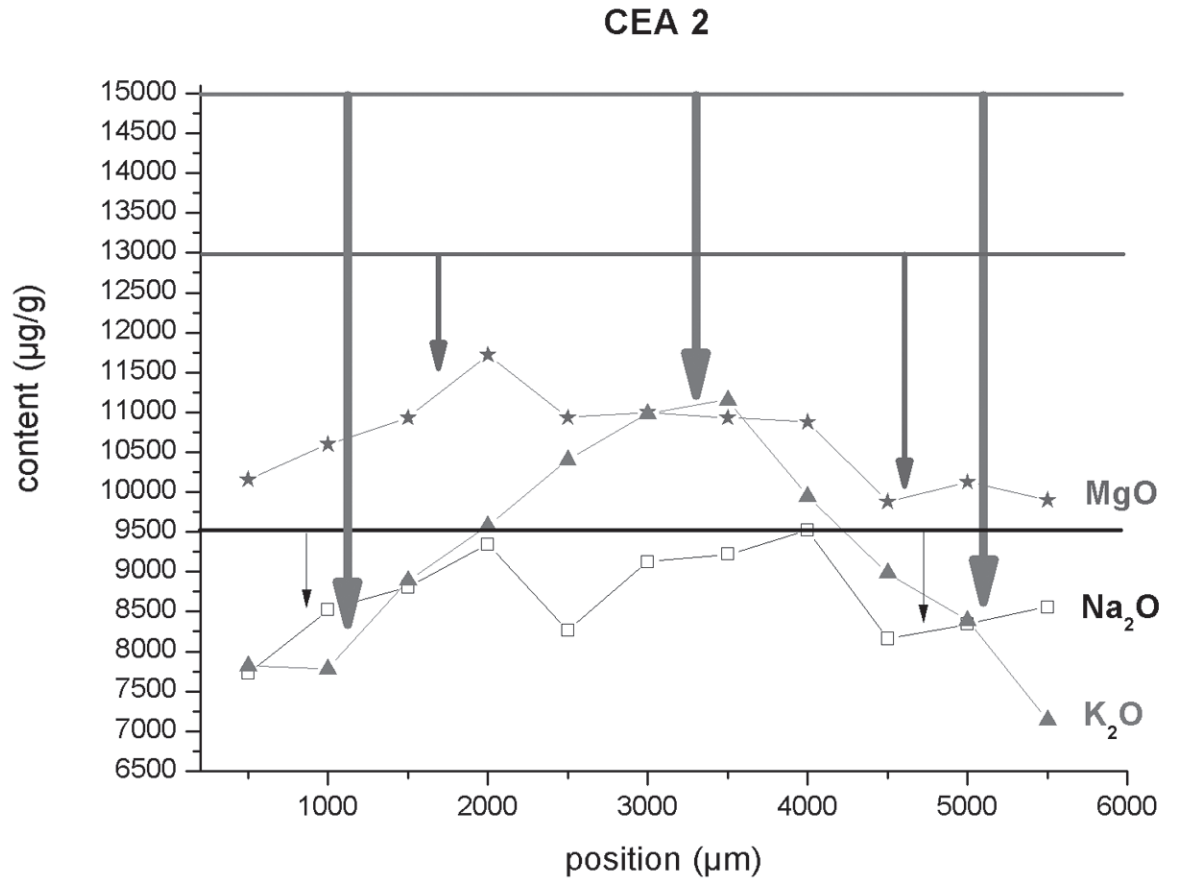

- Contamination of bone by potassium and silicon by the aging procedure itself.

- Loss of carbonate and a certain increase of apatite crystallinity induced by the artificial aging.

Additionally to these results, the aging treatment can be considered likely as interesting to study extreme degradation state of osseous tissue (collagen-poor brittle bone, no more mechanical resistance of the bone material). Nevertheless, the chosen aging protocol should not be suitable to simulate moderate degraded bone; but in this case, the consolidation treatment is perhaps less necessary.

\section{Consolidation procedure}

The selection criteria discussed previously to choose a convenient resin formulation to consolidate bone was validated for azelaic acid. Indeed, the artificially altered bone was consolidated by a treatment with azelaic acid.

Morphological investigations by electron microscope observations disclosed apparently a homogenous distribution of the consolidant, but cavities of the bone are kept unfilled. The consolidant seemed only to crystallize in thin layers at the inner walls of the Haversian channels.

Though there is no quantitative information on the organic matter, the FTIR investigation confirmed a consolidant distribution all over the sample.

According to the preliminary results of this study, a brief estimation of the applicability/efficiency of azelaic acid for the consolidation of bone was performed, with interesting results: rapidity of treatment, effective impregnation and consolidation of dense and brittle osseous tissue. Nevertheless, the consolidation treatment leads to a partial removal of potassium that was incorporated via the aging procedure. Additionally, sodium and magnesium get solved to a certain amount due to the acidity of consolidation treatment. The consolidation procedure seems to induce slight changes of the mineral phase, enhancing the crystallinity of the sample. However, the carbonate content seems not to be significantly changed by the treatment.

\section{Possible improvements of the consolidation procedure}

Consequently, the protocol must be optimized with regards to the used parameters, especially the temperature, the resin content and the duration, to find an acceptable compromise between the bone impregnation by azelaic acid and the acid attack of osseous mineral compounds by this resin during the impregnation process. Indeed, with an azelaic acid content lower than $90 \mathrm{wt} \%$, the permeation temperature may be chosen between $50-70^{\circ} \mathrm{C}$, a temperature less harmful than $90^{\circ} \mathrm{C}$.

Another interesting improvement axis could be the possibility to use a "partial basic form" of azelaic acid, i.e. to transform a part of carboxylic function $(-\mathrm{COOH})$ by the carboxylate function $\left(\mathrm{COO}^{-} \mathrm{Na}^{+}\right)$after reaction of acid by 
soda for instance. The acidic nature of the resin will decrease, but the hydrophobic nature too. A compromise must be assessed. Furthermore, the diffusion of the new resin formulation in bone must be checked.

\section{Conclusion}

An aging protocol was used to manufacture very degraded bone characterized by a total destruction of its collagen. This artificial alteration procedure allowed the preparation of model samples for subsequent research works in the field of bone conservation and consolidation. Azelaic acid was tested for its consolidation efficiency. Preliminary results of bone treatment from azelaic acid are promising. The characterization results of a first set of samples disclosed an effective impregnation in the bulk of the bone material.

Nevertheless, these preliminary experiments must be completed before a full validation of azelaic acid as bulking agent of bone. The study needs to be definitely based on a larger set of bone samples. The added value in terms of consolidation has to be assessed more accurately, namely by evaluating the improvement of the mechanical properties of the treatment and the reversibility of the consolidation. Furthermore, the alteration of the bone by the treatment and the long term aging of the combination between azelaic acid and mineral components of bone (hydroxi-apatite is basic) have to be studied more precisely. The treatment protocols must be optimized in terms of acidity, treatment temperature and resin content. Finally, the treatment protocol must be assessed using bone samples with different preservation states and finally using archaeological wet bone samples from various sites.

\section{Acknowledgements}

The authors acknowledge Julie Guttierez, Conservator of Historical Monuments, DRAC Pays de la Loire, for having provided the Crosier of the tomb of Hardouin de Bueil for a conservation study at the C2RMF. The AGLAE team of the $C 2 R M F$ is thanked for their support during the PIXE measurements. The authors are also very grateful for the financial support of this study by the ANR grant ArBoCo ANR-07JCJC-0149-01.

\section{References}

1. Smith, C. I., Nielsen-Marsh, C. M., Jans, M. M. E. and Collins, M. J., 2007 - Bone diagenesis in the European Holocene I: patterns and mechanisms. Journal of Archaeological Science. 34: p. 1485-1493.

2. Nielsen-Marsh, C. M., Smith, C. I., Jans, M. M. E., Nord, A., Kars, H. and Collins, M. J., 2007 - Bone diagenesis in the European Holocene II: taphonomic and environmental considerations. Journal of Archaeological Science. 34: p. 15231531.

3. Reiche, I., FaVre-Quattropani, L., Vignaud, C., Bocherens, H., Charlet, L. and Menu, M., 2003. A multi-analytical study of bone diagenesis: the Neolithic site of Bercy (Paris, France). Measurement Science and Technology. 14: p. 16081619.

4. Chadefaux, C., Vignaud, C., Menu, M., Reiche, I., 2008 - Effects and efficiency of consolidation treatments on Palaeolithic reindeer antler. Multi-analytical study by means of XRD, FT-IR microspectroscopy, SEM, TEM and $\mu$-PIXE/ PIGE analyses. Applied Physics A. 92: 171-177.

5. Hiron, X. and Hug, B., 2001 - Set up of a treatment procedure for a very large collection of antlers coming from the Neolithic sites of Chalain. In $8^{\text {th }}$ ICOM WOAM Conference. Stockholm. p. 601-604.

6. X. Hiron et al., 2004 - Results from treating hundred of waterlogged antlers - Study of material behaviour during impregnation and drying treatments. In 9th ICOM WOAM Conference. Copenhagen. p 473-482.

7. Weiner, S. and Bar-Yosef, O., 1990 - States of Preservation of Bones from Prehistoric Sites in the Near East: A Survey. Journal of Archaeological Science. 17: p. 187-196.

8. Wright, L. E. and Schwarcz, H. P., 1996. Infrared and Isotopic Evidence for Diagenesis of Bone Apatite at Dos Pilas, Guatemala: Palaeodietary Implications. Journal of Archaeological Science. 23: p. 933-944.

9. Calligaro, T. et al., 2004 - Review of accelerator gadgets for art and archaeology. Nuclear Instruments and Methods in Physics Research Section B. 226(1-2): p. 29-37.

10. Maxwell, J. A., Campbell, J. L. and Teesdale, W. J., 1988 - The Guelph PIXE Software. A description of the code package. Nuclear Instruments and Methods in Physics Research B. 43: p. 218-230. 